\title{
Middle cerebral artery stenosis associated with moyamoya pattern collateralization
}

\author{
Randall C. Edgell ${ }^{*}$, Alan S. Boulos ${ }^{2}$, Afshin Borhani Haghighi ${ }^{1,3}$, Gary L. Bernardini ${ }^{4}$ and Dileep R. Yavagal ${ }^{5}$ \\ 1 Department of Neurology and Psychiatry, Saint Louis University, Saint Louis, MO, USA \\ 2 Division of Neurosurgery, Neuroendovascular Section, Albany Medical Center, Albany, NY, USA \\ ${ }^{3}$ Research Center for Transgenic Technology, Shiraz University of Medical Sciences, Shiraz, Iran \\ ${ }^{4}$ Department of Neurology and Neurosurgery, Albany Medical Center, Albany, NY, USA \\ ${ }^{5}$ Department of Neurology, University of Miami, Miami, FL, USA
}

\section{Edited by:}

Jawad Kirmani, JFK Medical Center, USA

\section{Reviewed by:}

Steve Hoover, The University of Oklahoma, USA

Akram Shhadeh, The University of Oklahoma, USA

\section{${ }^{*}$ Correspondence:}

Randall C. Edgell, Department of Neurology and Psychiatry, Saint Louis University, 1438 Monteleone Hall, South Grand Boulevard, Saint Louis, MO 63104, USA.

e-mail: redgell@s/u.edu
Background and Purpose: Moyamoya disease is a well described phenomenon. This pattern of collateralization associated with isolated middle cerebral artery stenosis and the natural history of this entity have not been well described. Methods: Cerebral angiograms and CT angiograms performed between August 2004 and August of 2006 demonstrating moyamoya collateralization were retrospectively reviewed. All cases of middle cerebral artery stenosis associated with a rete pattern of collateralization were included in this series. Demographic, clinical, and angiographic data were obtained. Results: There were three cases of middle cerebral artery stenosis associated with a moyamoya pattern of collateralization. The average age of the patients was 36-years old, 2 were male, and all were Caucasian. All patients presented with ischemic symptoms. The average degree of stenosis was $91 \%$. No stenosis was seen in the supraclinoid internal carotid arteries or elsewhere in the intracranial vasculature. Conclusion: We describe an unusual pattern of anastomosis associated with isolated severe middle cerebral artery stenosis or occlusion in Caucasians.

Keywords: middle cerebral artery, moyamoya disease

\section{INTRODUCTION}

Moyamoya disease was first described by Takeuchi (1961). This disease is most prevalent in Japan were it is thought to affect up to $3 \%$ of the population (Kuroda et al., 2005) It is classically defined as bilateral occlusion at the terminal portion of the internal carotid artery together with an abnormal vascular network at the base of the brain. The name, moyamoya, means puff of smoke in Japanese and comes from the angiographic appearance of the abnormal vascular network at the base of the brain. (Takeuchi, 1961)The patho-physiology of moyamoya is thought to involve progression of stenosis or occlusion of the intracranial major arteries including the distal ends of the internal carotid artery as the primary lesion and the formation of the abnormal vascular network secondarily as collateral supply.(Fukui et al., 2000).

The moyamoya angiographic pattern has also been seen in association with stenoses in the posterior circulation and in association with a variety of vascular anomalies.(Kinoshita et al., 1998; Komiyama et al., 1999) There are less frequent reports of moyamoya pattern collateralization associated with middle cerebral artery occlusion in Japanese patients.(Fukawa et al., 1981, 1982; Morii et al., 1988; Sameshima et al., 2000; Seki et al., 2001) There are only two such reports in non-Japanese patients.(Zulch et al., 1974; Walsh et al., 1984) We report three patients with isolated middle cerebral artery stenosis or occlusion associated with moyamoya pattern collateralization in Caucasian patients.

\section{MATERIALS AND METHODS}

Cerebral angiograms and computed tomographic(CT) angiograms performed between August 2004 and August of 2006 in which the moyamoya pattern was observed were retrospectively reviewed. All cases of middle cerebral artery stenosis associated with a rete pattern of collateralization were included in this series. Demographic, clini$\mathrm{cal}$, and angiographic data were obtained.

\section{RESULTS}

There were three cases of middle cerebral artery stenosis associated with a moyamoya pattern of collateralization. The average age of the patients was 36 , two were male, and all were Caucasian. The symptoms that prompted cerebral angiography were ischemic in all cases. One case involved the right middle cerebral artery and one case involved the left middle cerebral artery, and one case involved both middle cerebral arteries. The average degree of stenosis was 91\% (Table 1). The anastomotic supply was through a fine network of basal ganglia perforating arteries that gave the pattern of a "puff of smoke" associated with moyamoya disease in two-dimensional (Figure 1) and three-dimensional CT angiography (Figure 2) and digital subtraction angiography (Figure 3). No stenosis was seen in the supraclinoid internal carotid arteries or elsewhere in the intracranial vasculature.

\section{DISCUSSION}

Moyamoya has been extensively studied, primarily in the Japanese population. Middle cerebral artery stenosis and moyamoya pattern collateralization has also been well described among Japanese 
Table 1 | Patient characteristics.

\begin{tabular}{|c|c|c|c|c|c|c|c|}
\hline Patient & Age & Sex & Race & $\begin{array}{l}\text { Presenting } \\
\text { findings }\end{array}$ & Risk factors & $\begin{array}{l}\text { Imaging } \\
\text { modality }\end{array}$ & Degree of stenosis \\
\hline 1 & 42 & $\mathrm{M}$ & Caucasian & $\begin{array}{l}\text { Recurrent L sided } \\
\text { weakness }\end{array}$ & Hyperlipidemia & $\begin{array}{l}\text { Catheter } \\
\text { angiogram }\end{array}$ & Occluded RMCA \\
\hline 2 & 23 & $\mathrm{M}$ & Caucasian & $\begin{array}{l}\text { R sided weakness/ } \\
\text { paresthesia }\end{array}$ & $\begin{array}{l}\text { Childhood } \\
\text { stroke }\end{array}$ & $\begin{array}{l}\text { Catheter } \\
\text { angiogram }\end{array}$ & 75\% LMCA Stenosis \\
\hline 3 & 42 & $F$ & Caucasian & $\begin{array}{l}\text { Bihemispheric } \\
\text { TIAs }\end{array}$ & $\begin{array}{l}\text { Tobacco, } \\
\text { obesity }\end{array}$ & $\begin{array}{l}\text { Catheter } \\
\text { angiogram }\end{array}$ & $\begin{array}{l}\text { Occluded RMCA; } 90 \% \\
\text { LMCA stenosis }\end{array}$ \\
\hline
\end{tabular}

M, male; L, left; $R$; right; MCA, middle cerebral artery; CT, computed tomography; CAD, coronary artery disease; TIA, transient ischemic attack.

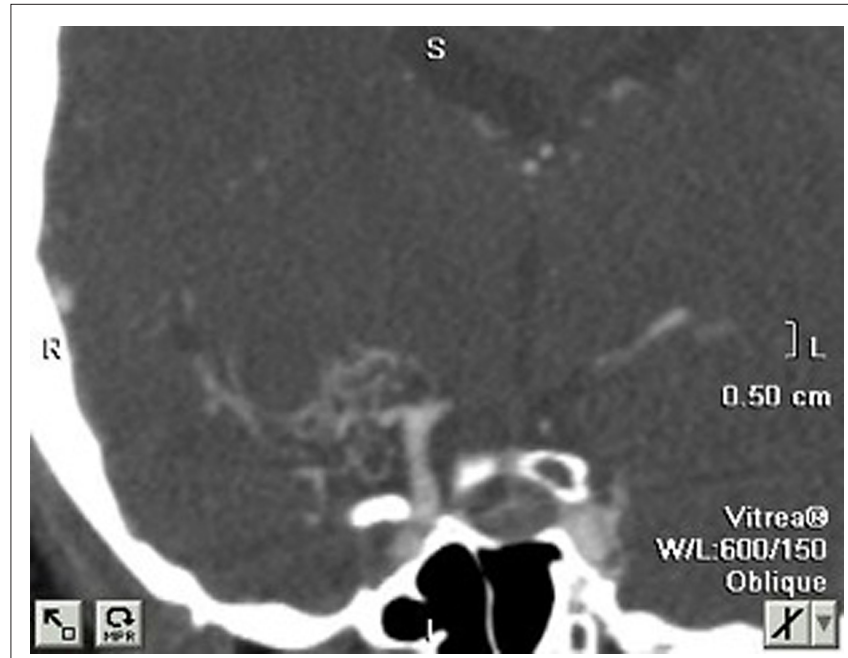

FIGURE 1 | Right middle cerebral artery stenosis and moyamoya phenomenon in non-reconstructed two-dimensional CT angiography.

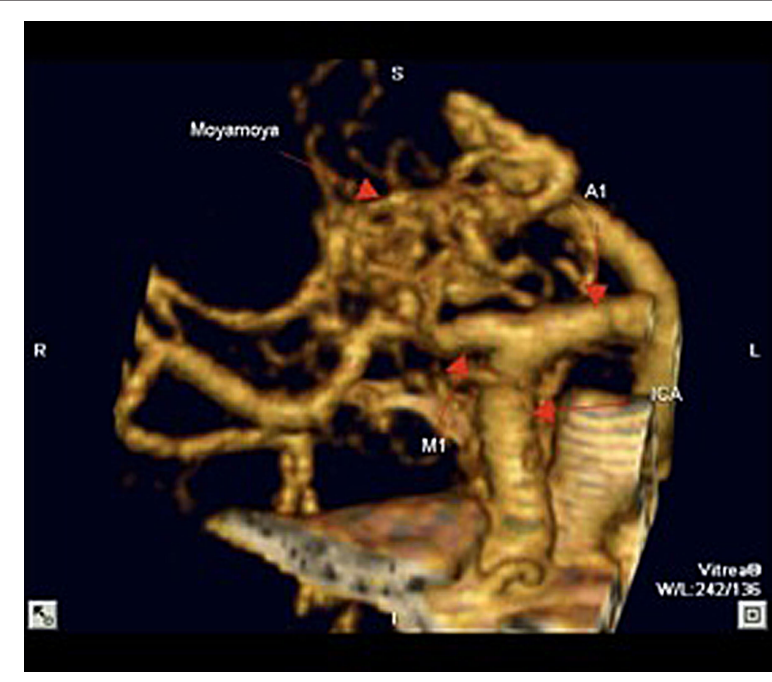

FIGURE 2 | Right middle cerebral artery stenosis and moyamoya phenomenon in reconstructed three-dimensional CT angiography.

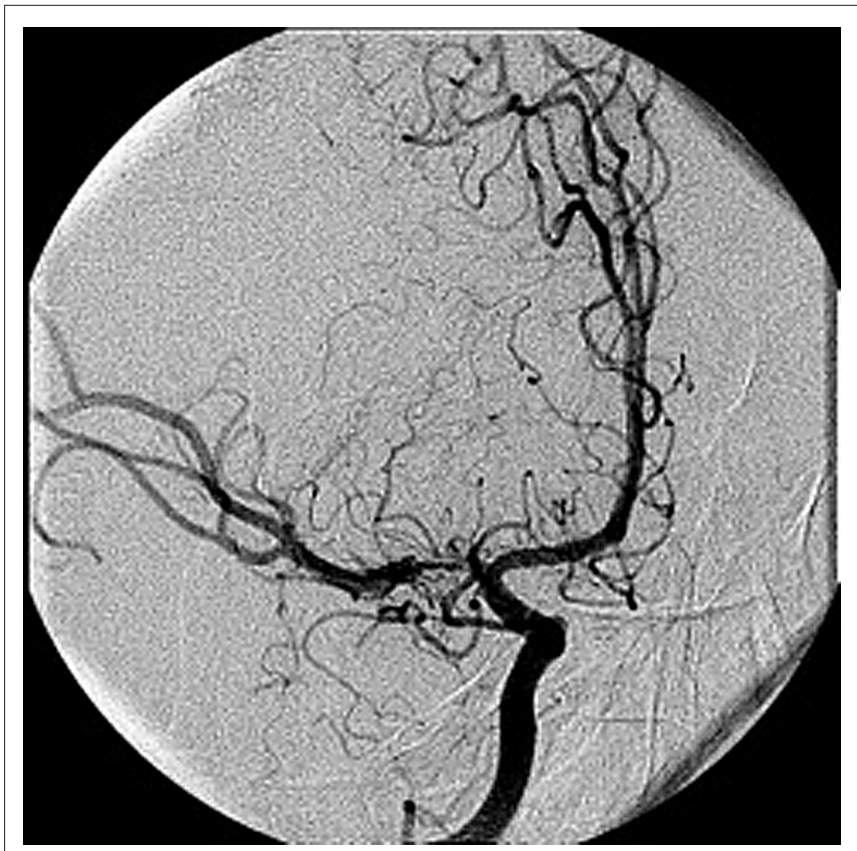

FIGURE 3 | Right middle cerebral artery stenosis and moyamoya phenomenon in PA view of right internal carotid contrast injection in digital subtraction angiography.

patients, but there are few reports in non-Japanese patients. (Fukawa et al., 1981, 1982; Morii et al., 1988; Sameshima et al., 2000; Seki et al., 2001) Moyamoya phenomenon, seen in association with middle cerebral artery occlusion in a non-Japanese patient was first described by Zulch et al. (1974). In this description a Caucasian patient was found to have carotid siphon stenosis as well as a middle cerebral artery occlusion and went on to develop a moyamoya pattern of collateralization 23 months later.(Zulch et al., 1974) The only report of isolated middle cerebral artery stenosis associated with moyamoya pattern collateralization in a non-Japanese patient was provided by Walsh et al. (1984) In this description a 12-year old Caucasian girl presenting with subarachnoid hemorrhage and a hematoma in the pineal region was found to have an arterial rete surrounding an occlusion of the left middle cerebral artery (Walsh et al., 1984). It is thought by Suzuki and Takaku (1969) that moyamoya disease is an 
acquired phenomenon that starts with progressive stenosis of the terminal internal carotid artery. This is followed by the formation of the compensatory collateral network that is responsible for the "puff of smoke" angiographic appearance.(Zipfel et al., 2005) The case described by Zulch et al. (1974) appears to support this hypothesis given the presence of carotid siphon stenosis and middle cerebral artery occlusion before the development of moyamoya collateralization 23 months later (Zulch et al., 1974). The patients described in this series all appeared to have atherosclerotic narrowing or occlusion of the middle cerebral artery that likely progressed slowly, allowing gradual formation of the collateral arterial network.

Patients with moyamoya disease are known to be at high risk for both hemorrhage and ischemia. Approximately half of adult patients will present with a hemorrhage (2) (Kuroda

\section{REFERENCES}

Fukawa, O., Aihara, H., Ishii, K., Kikuchi, J., Mashiyama, S., Katayama, M., and Kogure, T. (1981). "Middle cerebral artery occlusion with moyamoya phenomenon," In First Report: Clinical Course and Angiographical Findings. 10th Conference of Surgery for Cerebral Stroke, Tokyo, Japan.

Fukawa, O., Aihara, H., and Wakasa, H. (1982). Middle cerebral artery occlusion with Moyamoya phenomenon.-2nd report: report of an autopsy case. No Shinkei Geka 10, 1303-1310.

Fukui, M., Kono, S., Sueishi, K., and Ikezaki, K. (2000). Moyamoya disease. Neuropathology 20(Suppl), S61-S64.

Kinoshita, Y., Kohshi, K., and Yokota, A. (1998). Moyamoya disease of adult onset brain stem haemorrhage associated with bilateral occlusion of the vertebral arteries-case report. Acta Neurochir. (Wien) 140, 181-184.

Komiyama, M., Nakajima, H., Nishikawa, M., Yasui, T., Kitano, S., Sakamoto, H., and Fu, Y. (1999). High incidence of persistent primitive arteries in moyamoya and quasi-moyamoya diseases. Neurol. Med. Chir. (Tokyo) 39, 416-420; discussion 420-412.

Kuroda, S., Ishikawa, T., Houkin, K., Nanba, R., Hokari, M., and Iwasaki, Y. (2005). Incidence and clinical features of disease progression in adult moyamoya disease. Stroke 36, 2148-2153.

Morii, K., Satoh S., Sekiguchi, K., Watanabe, M., and Yamanaka R. (1988). Two cases of intraventricular hemorrhage accompanied with middle cerebral artery occlusion, moyamoya phenomenon, anterior choroidal artery peripheral aneurysm and choroid plexus angioma. Surg Cereb Stroke (Japan) 16: 395- 402.

Sameshima, T., Morita, Y., Yanagita, M., Nakano, S., Goya, T., and Wakisaka, S. (2000). Unilateral middle cerebral artery stenosis in an adult with Down's syndrome-case report. Neurol. Med. Chir. (Tokyo) 40, 216-219.

Seki, Y., Fujita, M., Mizutani, N., Kimura, M., and Suzuki,Y.(2001).Spontaneous middle cerebral artery occlusion leading to moyamoya phenomenon and aneurysm formation on collateral

et al., 2005). This poor natural history has led to aggressive attempts to revascularize the arterial segment downstream from the occlusion or stenosis (Suzuki and Takaku, 1969). The natural history of MCA stenosis or occlusion associated with moyamoya collateralization on the other hand is not known. All three patients in this study were discovered due to ischemic phenomenon. The development of collateral supply in these patients may serve as an endogenous bypass procedure and have a protective roll. Conversely, such patients may be at similarly high risk for stroke and hemorrhage as patients with moyamoya disease. Therefore, in the future it will be important to better delineate the natural history of isolated middle cerebral artery stenosis associated with moyamoya pattern collateralization in a larger group of patients.

arteries. Surg. Neurol. 55, 58-62; discussion 62.

Suzuki, J., and Takaku, A. (1969). Cerebrovascular "moyamoya" disease. Disease showing abnormal net-like vessels in base of brain. Arch. Neurol. 20, 288-299.

Takeuchi, K. (1961). Occlusive diseases of the carotid artery: especially on their surgical treatment. Shinkei Shimpo 5 , 511-542.

Walsh, J. W., Goldstein, S., and Dochtermann,D.(1984).Subarachnoid hemorrhage in an adolescent with spontaneous occlusion of the left middle cerebral artery and reconstruction by collateral vessels (Moyamoya phenomenon). Surg. Neurol. 21, 30-34.

Zipfel, G. J., Fox, D. J. Jr., and Rivet, D.J. (2005). Moyamoya disease in adults: the role of cerebral revascularization. Skull Base 15, 27-41.

Zulch, K. J., Dreesbach, H. A., and Eschbach, O. (1974). Occlusion of the middle cerebral artery with the formation of an abnormal arterial collateral system-moyamoya type-23 months later. Neuroradiology 7, 19-24.
Conflicts of Interest Statement: The authors declare that the research was conducted in the absence of any commercial or financial relationships that could be construed as a potential conflict of interest.

Received:07 May 2010; paperpending published: 13 July 2010; accepted: 10 August 2010; published online: 25 November 2010.

Citation: Edgell RC, Boulos AS, Haghighi AB, Bernardini GL and Yavagal DR (2010) Middle cerebral artery stenosis associated with moyamoya pattern collateralization. Front. Neur. 1:119. doi: 10.3389/ fneur.2010.00119

This article was submitted to Frontiers in Endovascular and Interventional Neurology, a specialty of Frontiers in Neurology. Copyright (C) 2010 Edgell, Boulos, Haghighi, Bernardini and Yaragal. This is an openaccess article subject to an exclusive license agreement between the authors and the Frontiers Research Foundation, which permits unrestricted use, distribution, and reproduction in any medium, provided the original authors and source are credited. 